\title{
Distribution of Water Monitor (Varanus salvator salvator) in Bellanwila-Attidiya Sanctuary, Sri Lanka
}

\author{
P.H.S.P. Chandrasiri*, W.A.D. Mahaulpatha \\ Department of Zoology, University of Sri Jayawardenepura \\ *spchandrasiri@gmail.com
}

\begin{abstract}
This study was conducted at the Bellanwila-Attidiya Sanctuary $\left(06^{\circ} 50^{\prime} \mathrm{N} 79^{\circ} 54^{\prime} \mathrm{E}\right)$ of western Province Sri Lanka from January 2013 to December 2013. Varanus salvator (Squamata: Varanidae) is a monitor lizard commonly inhabiting semi-aquatic habitats. V. salvator is widely distributed throughout Sri Lanka in wet, dry and intermediate zones below $500 \mathrm{~m}$ elevation. Global conservation status and national conservation status are both in the Least Concerned (LC) category.
\end{abstract}

The field was visited four days a month during the day time (08:00 to 18:00 hrs). Visual Encounter Studies (VES), and patch sampling was used along $200 \mathrm{~m}$ line transect for census. At the same time, reptile species observed were recorded. Four habitat types were distinguished according to dominant plant types, water cover percentage, grass cover percentage and floating vegetation percentage. The four habitats were identified as bog area with trees, muddy area with grass, slowly flowing canal and trees in the terrestrial habitat. Number of feedings and food types was recorded. During this period, number of garbage dumping sites in each habitat and area of the garbage sites were measured. Data analysis was done using Minitab ${ }^{\text {TM }} 14$ software.

Twenty eight reptile species were recorded in the present study. Relative abundance of $V$. salvator is $38.47 \%$ within the sanctuary. Total sightings of $V$. salvator during the study period were 1,219. Number of animal sightings was 373 from bog area with trees, 211 from muddy area with grass, 310 from slowly flowing canal and 325 from trees in the terrestrial habitat were recorded. The highest number $(07)$ and maximum area $\left(50 \mathrm{~m}^{2}\right)$ of garbage dumping sites were recorded from the habitat of bog area with trees. Of the 30 feeding observations that were recorded in this study, 28 feedings sightings observed were on garbage. Other two feedings were a domestic cat and a carcass of a monkey. There were threats to the domestic animals such as cats and dogs.

$V$. salvator is an indicator species of pollution because they are scavengers in the food chain. Higher abundance of $V$. salvator could be a threat of other amphibians, reptiles and birds because of their destructive and predatory behaviour.

Keywords: Bellanwila-Attidiya Sanctuary, Water monitor (Varanus salvator), Garbage, Pollution, Scavengers 